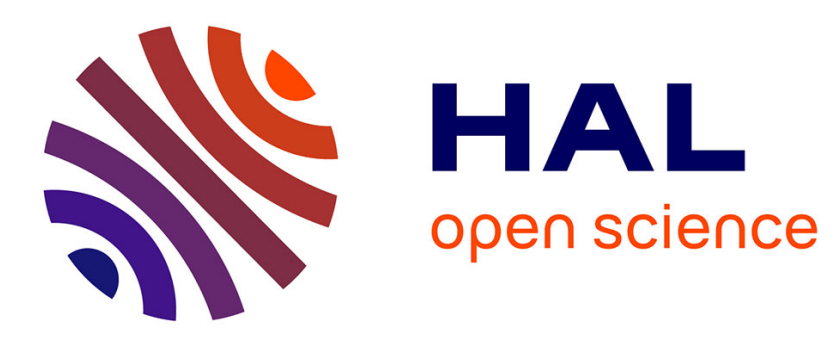

\title{
Hydroxyapatite-barium titanate piezocomposites with enhanced electrical properties
}

Mythili Prakasam, Marjorie Albino, Eric Lebraud, Mario Maglione, Catherine Elissalde, Alain Largeteau

\section{- To cite this version:}

Mythili Prakasam, Marjorie Albino, Eric Lebraud, Mario Maglione, Catherine Elissalde, et al.. Hydroxyapatite-barium titanate piezocomposites with enhanced electrical properties. Journal of the American Ceramic Society, 2017, 100 (6), pp.2621 - 2631. 10.1111/jace.14801 . hal-01539135

\section{HAL Id: hal-01539135 \\ https://hal.science/hal-01539135}

Submitted on 14 Jun 2017

HAL is a multi-disciplinary open access archive for the deposit and dissemination of scientific research documents, whether they are published or not. The documents may come from teaching and research institutions in France or abroad, or from public or private research centers.
L'archive ouverte pluridisciplinaire HAL, est destinée au dépôt et à la diffusion de documents scientifiques de niveau recherche, publiés ou non, émanant des établissements d'enseignement et de recherche français ou étrangers, des laboratoires publics ou privés. 


\title{
Hydroxyapatite -Barium titanate piezocomposites with enhanced electrical properties
}

Mythili Prakasam*, Marjorie Albino, Eric Lebraud, Mario Maglione, Catherine Elissalde and Alain Largeteau

CNRS, Université de Bordeaux, ICMCB 87 avenue du Dr. A. Schweitzer, F-33608 Pessac, France *e-mail: mythili.prakasam@icmcb.cnrs.fr/mythili.prakasam@gmail.com

\begin{abstract}
The present work aims to obtain Hydroxyapatite (HA) - Barium Titanate (BT) piezocomposites with improved electrical properties by retaining $\mathrm{OH}^{-}$ion and tuning $\mathrm{BT}$ grain size. Dense piezocomposites of HA-BT were obtained using single step Spark Plasma Sintering (SPS). The presence of $\mathrm{OH}^{-}$ions in the sintered piezocomposites of HA-BT was confirmed by high-temperature X-ray diffraction and Fourier transform infrared transmittance. No decomposition/ interaction between HA and BT phases were observed in the complete range of temperature studied. The dielectric and pyroelectric properties were studied as a function of temperature $(100 \mathrm{~K}$ to $450 \mathrm{~K})$ and frequency $(100 \mathrm{~Hz}$ to $2 \mathrm{MHz})$. The influence of the ferroelectric grain size $(300$ and $500 \mathrm{~nm}$ ) on the electrical properties of HA-BT has been analyzed. The dielectric permittivity of HA-BT ceramics can be enhanced with appropriate ferroelectric grain size and volume fraction of BT $(<80 \%)$.
\end{abstract}

Keywords: Biocomposites; Electrical properties; Dielectric; Pyroelectric

\section{Introduction}

Human bone has inherent electrical properties ${ }^{1}$ (pyroelectric, piezoelectric and polarization), which is considered to play a vital role in the bone healing/remodeling ${ }^{2}$. The occurrence of electric potentials under mechanical loading ${ }^{3}$ in bone is explained in terms of collagen ${ }^{4}$ and by ionic fluid movement ${ }^{5}$ in the structure. These electrical potentials corresponding 
to applied load regulate the mechanical adaptation of bone and bone cell activities, which lead to the idea of adding an electroactive element ${ }^{6}$ to the implant material to improve bone healing/ remodeling. Hydroxyapatite (HA) is one of the widely used synthetic material for the bone graft substitutes $^{7}$. Synthetic nanocrystalline HA has recently been demonstrated ${ }^{8}$ to exhibit piezo, pyro and ferroelectric property. A.Gandhi et $\mathrm{al}^{8}$ reported that a combination of optimized poling conditions and texture in HA has resulted in a longitudinal piezoelectric strain co-efficient that is one order higher than that of bone and of the same order as that of the uncalcified collagen in the tendon. $\mathrm{OH}^{-}$groups in $\mathrm{HA}$ are responsible for the polarization ${ }^{9}$ leading to piezoelectricity. Retention of $\mathrm{OH}^{-}$groups not only ensures the retention of the HA's chemical composition, but also helps in spontaneous polarization and high electrical conductivity exhibited by HA. Enhanced osteobonding and osteoconductive abilities of electrically polarized HA ceramic were reported ${ }^{10}$ upon implantation in the cortical bone of white rabbits. Re-orientation of $\mathrm{OH}^{-}$dipoles in $\mathrm{HA}$ is also attributed to the positive effect on the biological response of HA implants ${ }^{11}$.

The piezoelectric properties of $\mathrm{BaTiO}_{3}(\mathrm{BT})\left(\left(\mathrm{d}_{33}\right)\right.$ of $\left.\sim 191 \mathrm{pC} / \mathrm{N}\right)$ make this material a good candidate to enhance the bone formation in the complex physiological environment ${ }^{12}$. BT is a well-known ferroelectric material whose properties are strongly linked to both crystal structure and the microstructure ${ }^{13,14}$. The permittivity values and Curie temperature depend on grain size. Guodong Zhan et al $^{15}$ reported that the maximum value of dielectric permittivity at room temperature occurs at a grain size of close to $1 \mu \mathrm{m}$. Decreasing the grain size from 10 to $1 \mu \mathrm{m}$ leads to an increase of the dielectric permittivity $\left(\varepsilon_{\mathrm{r}}\right)$ reaching values higher than 5000 at room temperature. Below $1 \mu \mathrm{m}$ BT grain size, the permittivity decreases markedly with further decreasing the grain size ${ }^{16}$. To mimic bone's inherent electrical property, various piezocomposites with different percentages of BT content (100-x) HA- $\mathrm{x}$ BT $(\mathrm{x}=25,40,60,75$, 90) were 
conceptualized and designed ${ }^{17}$. 60HA-40BT and 40HA $-60 \mathrm{BT}$ are the two well-known, widely investigated biopiezocomposites ${ }^{18-21}$. No piezoelectric co-efficient was observed in the case of composites with $\mathrm{BT}$ content lower than $<80 \%{ }^{22}$. Increasing BT content, though increases mechanical toughness ${ }^{23}$ in HA-BT composites leads to increase of sintering temperature (> $950^{\circ} \mathrm{C}$ ). The increase of sintering temperature with the increase of BT content could cause the dissociation ${ }^{24}$ of $\mathrm{HA}$ leading to different phases such as $\beta$ - TCP/ $\alpha$ - TCP/ $\mathrm{CaTiO}_{3} / \mathrm{Ba}_{10}\left(\mathrm{PO}_{4}\right)_{6}$ $(\mathrm{OH})_{2}$ and loss of $\mathrm{OH}^{-}$in $\mathrm{HA}$.

Both porous $^{25}$ and dense piezocomposites of (100-x) HA - x BT are reported for their electroactivity. HA piezocomposites of alkali niobates is reported by Dubey et $\mathrm{a}^{26}$ to increase the electroactivity and to decrease the sintering temperature required to densify the piezocomposites. However, the room temperature values of the dielectric permittivity and loss for both of the developed composites ${ }^{27}, 60 \mathrm{HA}-40 \mathrm{BT}$, and 40HA-60BT, are 21 and 38 and 0.01 and 0.02, respectively. Significant improvement was recently reported by Dubey et al ${ }^{18}$ in HA-BT composites sintered at low temperature using spark plasma sintering (SPS) multi-step cycle.

In the present study, we focus on (100-x) HA- $x$ BT $(x=25,40,60,75)$ dense piezo biocomposites obtained by one-step SPS addressing two major issues: i) an experimental proof through IR and thermal characterizations that $\mathrm{OH}^{-}$are retained in dense $\mathrm{HA}-\mathrm{BT}$ composites, ii) a complete and reliable dielectric and pyroelectric investigation showing the enhancement of the dielectric properties by controlling ferroelectric phase content and ferroelectric grain size.

\section{Experimental procedure}

\section{II.1 Materials processing}

Pure HA was synthesized by suspension-precipitation method $^{28}$ mixed with the commercial barium titanate $\mathrm{BaTiO}_{3}$ (BT) from M/S Sakai with different sizes corresponding to 
mean diameters of $300 \mathrm{~nm}$ and $500 \mathrm{~nm}$. HA and BT were mixed in various wt\% ratios (100-x) HA - (x) BT, where $\mathrm{x}=25,40,60,75$ by rotation mixing (to avoid any influence from balls and milling jars) for $48 \mathrm{~h}$ to ensure a homogeneous mixture of both the compositions. Rotation mixing was used to avoid contamination. For the sake of simplicity 75HA-25BT, 60HA-40BT, 40HA-60BT and 25HA-75BT will be addressed hereafter as HB25, HB40, HB60, and HB75, respectively. To indicate the different grain size of BT used, the composites obtained with BT-300 nm will be addressed as $\mathrm{HB}_{300} 25, \mathrm{HB}_{300} 40, \mathrm{HB}_{300} 60$ and $\mathrm{HB}_{300} 75$ and the composites obtained with BT-500 nm will be indicated as $\mathrm{HB}_{500} 25, \mathrm{HB}_{500} 40, \mathrm{HB}_{500} 60$, and $\mathrm{HB}_{500} 75$, respectively.

\section{II.2 Sintering}

Spark plasma sintering (SPS) experiments were performed with DR. SINTER LAB Spark Plasma Sintering system, Model SPS-515S-FUJI. The experiments were performed under a vacuum of $10 \mathrm{~Pa}$ with the pulse sequence for the SPS applied voltage of 12:2 (i.e., 12 ON/ 2 OFF). $1 \mathrm{~g}$ of powder was used for each experiment. The experiment was carried out in a graphite mold with an inner diameter of $10 \mathrm{~mm}$ and an external diameter of $25 \mathrm{~mm}$. The internal of the graphite die was covered with flexible carbon paper (Papyex). The mold was covered with carbon fiber felt to limit the loss of heat radiation. The temperature of the mold was measured with the help of thermocouple. The pellets were sintered under vacuum by SPS at temperatures between $850^{\circ} \mathrm{C}-$ $900^{\circ} \mathrm{C}$ with a dwell time of 10 minutes under a uniaxial pressure of $100 \mathrm{MPa}$ in a single step process. The pressure was applied at the onset of the sintering cycle and released after cooling down to room temperature. The heating and cooling rate of $25^{\circ} \mathrm{C} / \mathrm{min}$ were maintained equal in all the experiments.

\section{II.3 Characterization studies}


Powder X-Ray Diffraction (XRD) analysis was performed with a PANalytical X'pert MDP diffractometer with $\theta-\theta$ Bragg-Brentano configuration with a backscattering graphite monochromator for $\mathrm{K}_{\alpha} \mathrm{Cu}$ radiation working at $40 \mathrm{kV}$ and $40 \mathrm{~mA}$. Temperature dependent XRD has been performed using a Powder diffractometer (PANalytical X'Pert Pro) equipped with a hightemperature chamber Anton Paar HTK16 $\left(1600^{\circ} \mathrm{C}\right)$ measuring with $\mathrm{K}_{\alpha} \mathrm{Cu}$ radiation. The starting powders and sintered samples were analyzed by XRD and temperature dependent XRD. The temperatures of analysis were from room temperature until $950^{\circ} \mathrm{C}$. The density was measured by the Archimedes method in distilled water. The microstructure was observed by a scanning electron microscope (Jeol 840 SEM) on the fractured surface without polishing. Fourier transform infrared (FTIR) measurements were carried out using a Bruker Equinox 55 spectrophotometer. The spectra were recorded over 32 scans in the range of $400-4000 \mathrm{~cm}^{-1}$, with a resolution of $4 \mathrm{~cm}^{-1}$, using $\mathrm{KBr}$ powder technique. Thermogravimetric analysis - mass spectrometry (TGA-MS) measurements were performed with an NETZSCH STA 409 apparatus coupled with a Thermostar Balzers Instruments quadrupole spectrometer. Thermogravimetry (TG) analyses were recorded in the $30-1000^{\circ} \mathrm{C}$ temperature range with a heating rate of $5^{\circ} \mathrm{C} \cdot \mathrm{min}^{-1}$ under argon. Dielectric measurements were performed using a Wayne-Kerr component analyzer 6425 in the temperature and frequency ranges of 200-500 K and $100 \mathrm{~Hz}-100 \mathrm{kHz}$ respectively. The mirror polished parallel faces of the pellets were electroded using gold sputtering and silver wires were attached to these electrodes using a silver paste. The real part of the permittivity derived from the capacitance was measured directly. For pyroelectric measurements, the sample was set in a homemade cell enabling the temperature to be scanned from $100 \mathrm{~K}$ up to $450 \mathrm{~K}$. Prior to such lowtemperature run, the cell was pumped down and a slight overpressure of dry Helium was introduced so as to avoid moisture adsorption. The sample was electrically connected to the output 
port of an HP4194 impedance analyzer with an operating frequency range of $100 \mathrm{~Hz}-2 \mathrm{MHz}$. The electrical polarization of the sample was measured after electrical poling $\left(E=1 \mathrm{kV} \mathrm{mm}^{-1}\right)$ of the samples performed at $130^{\circ} \mathrm{C}$ for $30 \mathrm{~min}$. The samples were then cooled down and the electric polarization was measured on heating.

\section{Results and discussion}

The aim of this work is to optimize the sintering of the composites by SPS by tuning the BT grain size and volume fraction. To enhance the electrical properties, obtaining high-density composites of HA- BT with various volume fractions of $\mathrm{BT}$ and retaining $\mathrm{OH}^{-}$ion is a prerequisite. Many studies have highlighted the decisive role of sintering to maintain the integrity of each phases of the composite and in particular to avoid HA decomposition. Wang et al. ${ }^{29}$, reported on morphology-enhanced nanostructured HA by conventional sintering with a dwell time of $24 \mathrm{~h}$ at $850^{\circ} \mathrm{C}$. The coalescence of fine particles is said to happen during calcination, which is expected to help in reducing the grain growth during sintering and allow easy molding for better shaping. Average grain sizes of $100 \mathrm{~nm}$ and $200 \mathrm{~nm}$ with improved mechanical properties by microwave sintering ${ }^{30}$ have been reported. SPS ${ }^{31}$ has been helpful in yielding nanostructured HA bioceramics with translucency with grain sizes below $200 \mathrm{~nm}$. A controlled heating rate has been employed by Uskokovic et al ${ }^{32}$ to obtain densification. Chen and Wang et al. ${ }^{33}$ used a two-step sintering method to obtain dense ceramic with the final stage of sintering through grain boundary diffusion and grain boundary migration. Fully-dense bioceramics with suppressed grain growth have been reported by Lukic et al ${ }^{34}$. The processing of HA under vacuum leads to the decomposition of HA while processing under the high partial pressure of water prevents decomposition. On the other hand, the presence of water in the sintering atmosphere inhibits densification of $\mathrm{HA}$ and accelerates the grain growth $^{35}$. The densification of HA attains a saturation limit between $1100{ }^{\circ} \mathrm{C}$ and $1300{ }^{\circ} \mathrm{C}$. Dehydroxylation ${ }^{36}$ leads to decomposition, and this $\mathrm{OH}^{-}$ion loss cannot be restored during cooling 
to ambient temperature. The dielectric constant of dry human cortical bone is around 10 and was found to be very sensitive to water content ${ }^{37,38,39}$. In general, dehydroxylation tends to occur at temperatures lower than $800{ }^{\circ} \mathrm{C}$, followed by accelerating dehydroxylation between 800 and 1350 ${ }^{\circ} \mathrm{C}$. At a temperature higher than $1350{ }^{\circ} \mathrm{C}$, irreversible dehydroxylation accompanied by decomposition occurs; whereas densification at a temperature $>900{ }^{\circ} \mathrm{C}$ takes place. Owing to the different densification behaviors of HA and BT, a balance has to be found in the selection of the sintering temperature. The high temperature leads to decomposition and phase instability in addition to impairing the mechanical properties of the HA-BT composite. Hence, sintering of HABT composite at low temperatures and short time duration is mandatory to retain the nanograins within the densified ceramic, and thus ensure better osteointegration and capability of nano-HA to release calcium and phosphate ions at the damaged site. $\mathrm{HB}_{300} 25, \mathrm{HB}_{500} 25, \mathrm{HB}_{300} 40, \mathrm{HB}_{500} 40$, $\mathrm{HB}_{300} 60, \mathrm{HB}_{500} 60$, were sintered at $850^{\circ} \mathrm{C}$ and compositions of $\mathrm{HB}_{300} 75$ and $\mathrm{HB}_{500} 75$ were sintered at $900^{\circ} \mathrm{C}$ (due to the composite rich in BT). High pressure has aided in significantly increasing the densification, enabling the composite to be fabricated under relatively lower temperature and shorter sintering period while obtaining dense composites. After sintering no carbon contamination was detected in the SPS samples. The chosen sintering cycle in the present work helped in obtaining the sample with good mechanical resistance. The sintered samples were ground and polished to a thickness of $1 \mathrm{~mm}$ discs.

The relative density of the composites measured by Archimedes method were in the range of $90 \%$. The density of the composites decreases with the increase content of BT due to the high densification temperature required for BT, which is in accordance with the previous reports ${ }^{17,18}$. An increase of density could be obtained by increasing the sintering temperature but low temperature was intentionally employed in this work to retain $\mathrm{OH}^{-}$ions in the lattice of the $\mathrm{HA}$ - 
BT composites. Hence, the HA-BT composites in the present study was chosen to be sintered between $850^{\circ} \mathrm{C}-900^{\circ} \mathrm{C}$ by SPS.

Phase stability and structure of HA-BT was studied with high-temperature XRD (Figure 1). Decomposition of HA starts at $1000^{\circ} \mathrm{C}$ under vacuum. While, dehydroxylation of HA is reported to start at $850^{\circ}-900^{\circ} \mathrm{C}$. The hexagonal HA and tetragonal BT phases have been identified in the XRD patterns of all (100-x) HA - (x) BT composites. The two Bragg peaks located around 44 to $46^{\circ}$ corresponding to the (002) and (200) planes of the tetragonal phases of BT were identified in all the composites of HA-BT. In all the composites of HA-BT, Bragg angle of (002) peak decreased and (200) shifted slightly to a high angle, which indicates that there is an increase in tetragonal distortion with the increase in grain size. It has to be noted that tetragonal distortion is related to spontaneous polarization and the decrease of grain size reduces also the noncentrosymmetric character of BT. Neither decomposition/ phase change nor additional phases resulting from interfacial reactions were detected in the chosen temperature range up to $900^{\circ} \mathrm{C}$ (Figure 1 (a)). XRD patterns on the monoliths (Figure 1 (b)) irrespective of their composition confirms the sole presence of the constituent phases of HA and BT. The tetragonal phase of BT was retained for all the sintered monoliths whatever the BT content. However, the broadening of the peaks in the sintered monoliths around the $44-46^{\circ}$ could be attributed to a resulting slight distortion from the compressive stress applied during SPS.

Enhanced bone osteobonding and new bone growth on polarized HA was attributed due to the generation of permanent surface charge ${ }^{40}$. At high temperatures under applied electric field, the surface charge is created in HA due to the proton migration in columnar $\mathrm{OH}^{-}$structure as opposed to dipole rotation. The orientation of the $\mathrm{OH}^{-}$ions ${ }^{41}$ in the channel can also cause a profound effect on the bonding strength. After sintering the composites at high temperatures, they 
are susceptible to loss of $\mathrm{OH}^{-}$ions. In order to identify the presence of $\mathrm{OH}^{-}$ions in the composites sintered by SPS, Fourier transform infrared (FTIR) transmittance measurements were carried out on the starting powders and on the sintered piezocomposites. Figure 2 indicates the FTIR spectrum of the sintered piezocomposite of (100-x) HA - (x) BT. It can be inferred that the FTIR spectrum consists of all the peaks corresponding to the initial powder used for densification confirming no loss of $\mathrm{OH}^{-}$or other significant chemical constituents of the composites. HA is characterized by the presence of $\mathrm{PO}_{4}{ }^{3-}, \mathrm{OH}^{-}, \mathrm{CO}_{3}{ }^{2-}$ groups and $\mathrm{BT}$ is characterized by the groups corresponding to Ti-O with $\mathrm{Ba} . \mathrm{PO}_{4}{ }^{3-}$ group is observed as the intense IR absorption bands at $580 \mathrm{~cm}^{-1}$ and $610 \mathrm{~cm}^{-}$ ${ }^{1}$ related to triply degenerated bending mode, $985 \mathrm{~cm}^{-1}$ corresponding to the non-degenerate symmetric P-O stretching and the peaks corresponding to $1050-1110 \mathrm{~cm}^{-1}$ is related to triply degenerated anti-symmetric P-O stretching. Adsorbed water on the surface is relatively wide and is observed from $2300-3300 \mathrm{~cm}^{-1}$ and the intense peak at $3567 \mathrm{~cm}^{-1}$ corresponds to $\mathrm{OH}^{-}$stretching vibration and the weak peak at $633 \mathrm{~cm}^{-1}$ are related to $\mathrm{OH}$ - librational vibration mode. $\mathrm{CO}_{3}{ }^{2-}$ groups are identified by intensive peaks between 1465 and $1480 \mathrm{~cm}^{-1}$ and peaks at $1544 \mathrm{~cm}^{-1}$. The bands at $\sim 880 \mathrm{~cm}^{-1}, \sim 1413 \mathrm{~cm}^{-1}$, and $\sim 1450 \mathrm{~cm}^{-1}$ are not used to identify carbonated apatite since they may also result from carbonate absorption on surfaces of apatite crystals or separated carbonate phase present with apatite crystals. Strong and wide band located between $495 \mathrm{~cm}^{-1}$ to $850 \mathrm{~cm}^{-1}$ indicates the presence of BT. Strong IR bands at $491 \mathrm{~cm}^{-1}$ and $580 \mathrm{~cm}^{-1}$ correspond to the tetragonal BT phases. The former is related to $\mathrm{TiO}_{6}$ stretching vibration that connects to barium ion and the latter confirms the Ti-O polarization in BT with tetragonal phase. The only difference observed between the starting powder and the sintered composite is the disappearance of the wide peak area between $2300-3300 \mathrm{~cm}^{-1}$ corresponding to the adsorbed surface water. None of the other bands 
change between the starting powder and the sintered composite, asserting the presence of OH- ion in the lattice of the sintered composite at the chosen sintering temperature.

In agreement with FTIR analyses, thermogravimetric analyses (TGA) (Figure 3) on the biocomposites confirm the absence of decomposition in the range of sintering temperature employed in the present study. Figure 3 (a) and (b) shows $\mathrm{HB}_{300} 40$ and $\mathrm{HB}_{500} 40$ biocomposites as a representative example for other piezocomposites investigated in the present study. Dehydration occurs in the temperature range of $35-800^{\circ} \mathrm{C}$ for $\mathrm{HA}$. Irrespective of the BT grain size, it can be observed from figure 3 that there is a continuous weight loss in the temperature range of 100$855^{\circ} \mathrm{C}$ with a mass loss of $-1.37 /-1.47 \%$. There is another temperature zone between $950-1150^{\circ} \mathrm{C}$ with a rapid decrease in mass of about $-1.23 /-1.77 \%$. The weight loss observed is mainly due to the loss of adsorbed surface water, loss of water of crystallization and breakage of $\mathrm{CO}_{3}{ }^{2-}$ and $\mathrm{HPO}_{4}$, which is in accordance with FTIR analyses on these composites.

Figure 4 shows the microstructure and electron diffraction scattering (EDS) images of the sintered piezocomposites of HB25 and HB75. Similar microstructural features are observed in HB40 and HB60. The microstructural investigation of the piezocomposites indicates grain growth of HA matrix is in the range of $400-500 \mathrm{~nm}$ from its initial grain size of $100 \mathrm{~nm}$. The grain growth corresponding to BT grains with an initial grain size of $300 \mathrm{~nm}$ and $500 \mathrm{~nm}$ is in the range of 400$500 \mathrm{~nm}$ and 600-700 nm, respectively. EDS images of the composites reveals the distribution of the HA (appearing black in back scattered images) and BT. It can be inferred that when BT $\geq 75$ weight $\%$, the distribution of HA in the composites becomes inhomogeneous. Piezoelectric effect can be enhanced in ceramics through preferred grain-orientation prior to poling process ${ }^{42,43}$.

Ceramics fabricated with SPS can yield texturing effect ${ }^{44}$. Further nanostructured ceramics will easily undergo plastic deformation in the presence of pulsed electric current ${ }^{45}$. In the present study, 
in addition to the plastic deformation, the texturing effect could be also caused by the thermal gradient within the sample due to the higher electrical resistivity of BT than HA. Individual HA particles tend to have in-plane c-axis orientation and the grain growth of these particles are restricted by SPS technique due to the uniaxial pressure involved in this process. Gandhi et al ${ }^{46}$ attributed a combined thermal-electrical energy from the localized plasma to ensure grain rotation despite grain growth restriction in the uniaxial pressure direction.

The nanostructured composites obtained in figures 4 and 5 can be attributed to the chosen spark plasma sintering conditions in the present work. The HA grains are well oriented in the direction perpendicular to the direction of application of pressure in SPS. The magnified image of the sample containing $\mathrm{HB}_{300} 40$ and $\mathrm{HB}_{500} 40$ in figure 5 indicates that there is no interdiffusion between the HA and BT layers. Further, it can be observed that the zone containing the HA is densified well, with distinct grain boundaries and the zone containing the BT is less densified, irrespective of their initial grain size. This can be attributed to the low sintering temperature employed in this study.

Dielectric measurements have been performed as a function of temperature and frequency for all the sintered biocomposites. Figure 6 (a) and (b) shows the dielectric permittivity as a function of temperature and figure 6 (c) shows a representative trend of dielectric loss as a function of temperature for different HA-BT compositions through composites of HB40 and HB60. As expected, the highest values of permittivity are obtained from the composite containing 75\% BT. Maximum values of about 260 at room temperature, higher than those reported in literature, are obtained despite the density of the ceramic of about $90 \%$. Permittivity decreases when increasing HA content down to 15-20 for HB25. It is worth noting that a maximum of permittivity is observed close to $400 \mathrm{~K}$. Ferroelectric Curie temperatures and dielectric permittivity at $250 \mathrm{~K}$ and $408 \mathrm{~K}$ of 
sintered composites is given in table 1. This signature of the ferroelectric-paraelectric transition is clearly marked for the highest content in BT and becomes masked by the high temperature conductivity for lower content of BT (i.e. increase of HA content). A frequency dispersion is observed when the temperature increases from room temperature. This frequency dependence of the relative permittivity becomes dominant with the increase of HA content due to the contribution of $\mathrm{OH}^{-}$ions to $\mathrm{HA}$ polarization ${ }^{47-49}$. Such dispersion could also arise from the reduction of the sintered piezocomposites of BT under SPS processing $\left(\mathrm{Ti}^{4+}\right.$ partially reduced in $\mathrm{Ti}^{3+}$ during sintering under low oxygen partial pressure). Dubey et $\mathrm{al}^{18,27}$ and Bowen et $\mathrm{al}^{22}$ reported that composites with BT content $\leq 60 \mathrm{wt} \%$ exhibit the lowest values $(<40)$ of dielectric permittivity. The room temperature values of dielectric permittivity and loss for highly densified HB40, and HB60 composites (98\%) are 21, 38 and 0.01 and 0.02 respectively. In the present work, we have demonstrated that the obtained values of the sintered HA-BT piezocomposites are significantly higher (nearly double -i.e. about 40 for HB40 and 70 for HB60- losses at $10 \mathrm{kHz}$ are about 0.02) than the reported values in the literature ${ }^{17,18,22,21,25,27}$. Remarkably, whatever the BT content, the dielectric permittivity decreases with the increase of BT grain size. This cannot be attributed to a change in density, but could be explained by a more homogeneous BT matrix when the initial BT grain size is smaller (300nm) (Figure 4). Our dielectric results also reveal an increase of the dielectric losses with increasing $\mathrm{BT}$ grain size. In the low temperature range $(\mathrm{T}<300 \mathrm{~K})$, the permittivity values become stable and independent of both temperature and frequency.

The pyroelectric behavior of $\mathrm{HA}, \mathrm{HB}_{300} 40$ and $\mathrm{HB}_{500} 40$ piezocomposites are shown in figure 7. It can be observed that the spontaneous polarization $\left(\mathrm{P}_{\mathrm{s}}\right)$ corresponding to $\mathrm{HB}_{300} 40$ and $\mathrm{HB}_{500} 40$ is $0.3 \mu \mathrm{C} / \mathrm{cm}^{2}$ and $0.6 \mu \mathrm{C} / \mathrm{cm}^{2}$, respectively. Whereas no pyrocurrent was detected for $\mathrm{HA}$ (Figure 7 (a)). Poling temperature is a dominant factor in controlling the property of HA electrets ${ }^{50}$ 
because the protonic conductivity exponentially changes with temperature. The high stiffness of the HA matrix impede the efficiency of the poling process which restricts the $90^{\circ}$ reorientations of the domain on poling. It is worth noting the significant change of HA microstructure of within the composite after poling. Grain boundaries clearly evidenced before poling are no more visible in the poled composites (Figure 5). This unexpected change of microstructure could be related to the modification of the grain boundaries due to surface charge accumulation. Under electric field, diffusion of protons induces formation dipoles in HA and leads to space charges in the vicinity of grain boundaries. The polarized state remains stable even at room temperature if the electric field is steadily applied during the cooling process after poling. A deeper analysis of both poling conditions and microstructure must be conducted in order to explore such unusual field effect on microstructure and evaluate the potentiality of these piezocomposites for tissue engineering applications. The investigation of this aspect is currently in progress.

\section{Conclusion}

In summary, we demonstrate the feasibility of obtaining improved dielectric properties of dense piezocomposites of $(100-\mathrm{x})$ HA- $\mathrm{x}$ BT $(\mathrm{x}=25,40,60,75,90)$ even at $\mathrm{x}<80 \%$ by controlling the grain size of BT particles in the range of $500 \mathrm{~nm}-1 \mu \mathrm{m}$. Dense piezocomposites of HA-BT have been fabricated by spark plasma sintering at temperatures $<900^{\circ} \mathrm{C}$ by a single step process without structural phase change, interdiffusion at interfaces or decomposition as shown by X-ray diffraction analyses Our process allows the retention of $\mathrm{OH}$ - ions in the HA-BT composites as confirmed by FTIR analyses. The influence of ferroelectric BT grain size in the HA-BT composites on the electrical properties was studied. Dielectric characterizations conducted in a large temperature range have shown that a stable permittivity value as high as 260 is obtained in HABT composites starting with $300 \mathrm{~nm}$ initial BT grain size and a BT content lower than $80 \%$. 
Furthermore, the signature of both the ferroelectric Curie temperature close to $400 \mathrm{~K}$ and the tetragonal -orthorhombic transition in the vicinity of room temperature was evidenced in this composite. The controlled BT grain size and the benefit of $\mathrm{OH}$ - retention within HA-BT composite are ascribed to such enhanced dielectric properties. An optimisation of the poling process should allow to understand the surface polarization of HA-BT, which could lead to tuning these piezocomposites as viable electroactive ceramics. Further investigations such as in-vitro and in vivo tests are in progress to validate the $\mathrm{OH}^{-}$ion influence and effect of ferroelectric grain size on electroactivity on the piezocomposites. The present study warrants the possibility to obtain significant electrical properties with more percentage of HA and less electroactive external components such as BT.

\section{Acknowledgment}

The authors thank Dr. Bikramjit Basu of IISc, India for providing HA nanopowders for this work. The authors thank Mr. A. Fargues, Mr. D. Denux and Ms. S. Buffiere for their assistance in FTIR, thermal analyses, and HR-SEM measurements, respectively.

\section{References}

${ }^{1}$ S.Singh, S.Saha, "Electrical properties of bone. A review," Clin Orthop Relat Res.,186 249-271 (1984).

${ }^{2}$ M. Lind, "Growth factor stimulation of bone healing. Effects on osteoblasts, osteomies, and implants fixation," Acta Orthopaedica Scandinavica Supplementum., 283 2-37 (1983).

${ }^{3}$ J. Klein-Nulend, R.G. Bacabac, and A.D. Bakker, "Mechanical loading and how it affects bone cells: The role of osteocyte cytoskeleton in maintaining our skeleton," European Cells and Materials 24 278-291 (2012).

${ }^{4}$ Andrew C. Ahn andAlan J. Grodzinsky, "Relevance of collagen piezoelectricity to "Wolff"s law": A critical review", Med Eng Phys. 31(7) 733-741 (2009).

5 D.C.Trumbore, W.J. Heideger, K.W. Beach, "Electrical potential difference across bone membrane", Calcified Tissue International, 32 (1) 159-168, (1980).

${ }^{6}$ Samuel Itay, "Compositions and methods for repair of cartilage and bone”, US Patent 4,904,259, 1990.

${ }^{7}$ Christopher J. Damien and J. Russell Parsons, "Bone graft and bone graft substitutes: A review of current technology and applications", Journal of Applied Biomaterials, 2(3) 187-208 (1991). 
${ }^{8}$ Abbasi A. Gandhi, Maciek Wojtas, Sidney. B. Lang, Andrei L. Kholkin and Syed A. M. Tofail, "Piezoelectricity in Poled Hydroxyapatite Ceramics", Journal of the American Ceramic Society, 97 (9) 2867-2872 (2014).

${ }^{9}$ S. B. Lang, S. A. M. Tofail, A. L. Kholkin, M. Wojtaś, M. Gregor, A. A. Gandhi, Y. Wang, S. Bauer, M. Krause and A. Plecenik, "Ferroelectric Polarization in Nanocrystalline Hydroxyapatite Thin Films on Silicon", Scientific Reports 3:2215 1-6 (2013).

${ }^{10}$ Hideki Sagawa, Soichiro Itoh, Wei Wang and Kimihiro Yamashita, "Enhanced Bone Bonding of the Hydroxyapatite/ $\beta$-Tricalcium Phosphate Composite by Electrical Polarization in Rabbit Long Bone", Artificial Organs, 34 (6) 491-497 (2010).

${ }^{11}$ Kimihiro Yamashita, Noriyuki Oikawa, and Takao Umegaki, "Acceleration and Deceleration of Bone-Like Crystal Growth on Ceramic Hydroxyapatite by Electric Poling", Chem. Mater., 8 (12) 2697-2700 (1996).

${ }^{12}$ Shepard Roberts, "Dielectric and Piezoelectric Properties of Barium Titanate”, Phys. Rev. 71890 -895 (1947).

${ }^{13}$ M. H. Frey and D. A. Payne, "Grain-size effect on structure and phase transformations for barium titanate", Phys. Rev. B 54 3158- 3168 (1996).

${ }^{14} \mathrm{Q}$. Jiang, X. F. Cui, and M. Zhao, "Size effects on Curie temperature of ferroelectric particles", Applied Physics A, 78(5) 703-704 (2002).

${ }^{15}$ Guodong Zhan, Amiya K. Mukherjee, Joshua D. Kuntz, Julin Wan, "High density barium titanate of high permittivity", US 20040201137A1 (2004).

${ }^{16}$ Dipankar Ghosh, Akito Sakata, Jared Carter, Pam A. Thomas, Hyuksu Han, Juan C.Nino, and Jacob L. Jones, "Domain wall displacement is the origin of superior permittivity and piezoelectricity in BT at intermediate grain sizes", Advanced functional materials, 24 (7) 885- 896 (2014).

${ }^{17}$ Frances R. Baxter, Irene G. Turner, Christopher R. Bowen, Jonathan P. Gittings, Julian B. Chaudhuri, "An in vitro study of electrically active hydroxyapatite-barium titanate ceramics using Saos-2 cells", Journal of Materials Science: Materials in Medicine, 20 (8) 1697-1708 (2009).

${ }^{18}$ A.K. Dubey, E.A. Anumol, K. Balani, and B. Basu, "Multifunctional Properties of Multistage Spark Plasma Sintered HA-BaTiO3-Based Piezobiocomposites for Bone Replacement Applications", J. Am. Ceram. Soc., 96 (12) 3753-3759 (2013).

${ }^{19}$ Haixin Zhao, Wenjun Dong, Yingying Zheng, Aiping Liu, Juming Yao, Chaorong Li, Weihua Tang, Benyong Chen, Ge Wang, Zhan Shi, "The structural and biological properties of hydroxyapatite-modified titanate nanowire scaffolds", Biomaterials, 32(25) 5837-5846 (2011).

${ }^{20}$ Hoda Zarkoob, Saeed Ziaei-Rad, Mohammad hossein Fathi and Hossein Dadkhah, "Synthesis, Characterization and Bioactivity Evaluation of Porous Barium Titanate with Nanostructured Hydroxyapatite Coating for Biomedical Application”, Advanced Engineering Materials, 14 (6) B322-B329 (2012).

${ }^{21}$ F. R. Baxter, C. R. Bowen, I. G. Turner, A. C. E. Dent, "Electrically Active Bioceramics: A Review of Interfacial Responses", Annals of Biomedical Engineering, 38(6) 2079-2092 (2010).

${ }^{22}$ C. R. Bowen, J. Gittings, I. G. Turner, F. Baxter and J. B. Chaudhuri, "Dielectric and piezoelectric properties of hydroxyapatite-BaTiO3 composites", Appl. Phys. Lett. 89 132906132909 (2006)

${ }^{23}$ X.M. Chen, B.Wang, “A new approach for toughening of ceramics”, Mater. Lett. 33 237-240 (1997).

${ }^{24}$ Y.W. Gu, N.H. Loh, K.A. Khor, S.B. Tor, P. Cheang, "Spark plasma sintering of hydroxyapatite powders", Biomaterials 23 37-43(2002). 
${ }^{25}$ Yan Zhang, Liangjian Chen, Jing Zeng, Kechao Zhou, Dou Zhang, “Aligned porous barium titanate/hydroxyapatite composites with high piezoelectric coefficients for bone tissue engineering”, Materials Science and Engineering: C, 39(1) 143-149 (2014).

${ }^{26}$ Ashutosh Kumar Dubey, Ryota Kinoshita and Ken-ichi Kakimoto, "Piezoelectric sodium potassium niobate mediated improved polarization and in vitro bioactivity of hydroxyapatite", RSC Adv., 5 19638-19646 (2015).

${ }^{27}$ A. K. Dubey, B.Basu,K.Balani,R. Guo, and A. S. Bhalla, "Dielectric and Pyroelectric Properties of HAp-BaTiO3 Composites", Ferroelectrics, 423 63-76 (2011).

${ }^{28}$ M. H. Santos, M. Oliveira, L. P. F. Souza, H. S. Mansur, and W. L. Vasconcelos, "Synthesis control and characterization of hydroxyapatite prepared by wet precipitation process", Mater. Res. 7 625-630 (2004).

${ }^{29}$ J.Wang, L.L. Shaw, "Morphology-Enhanced Low-Temperature Sintering of Nanocrystalline Hydroxyapatite", Adv. Mater. 19 2364-2369 (2007).

${ }^{30}$ Đ.Veljovic, I.Zalite, E.Palcevskis, I. Smiciklas, R.Petrovic, D. Janackovic, "Microwave Sintering of Fine Grained HAP and HAP/TCP Bioceramics", Ceram. Int. 36 595-603 (2010).

${ }^{31}$ M.Eriksson, Y.Liu, J.Hu, L.Gao, M. Nigren, Z. Shen, "Transparent Hydroxyapatite Ceramics with Nanograin Structure Prepared by High Pressure Spark Plasma Sintering at the Minimized Sintering Temperature", J. Eur. Ceram. Soc. 311533-1540 (2011).

${ }^{32}$ D.P.Uskokovic, H.Palmour, R.M. Spriggs, Eds.; Science of Sintering, New Directions for Materials Processing and Microstructural Control; Plenum Press: New York, NY, USA; London, UK, 1989.

${ }^{33}$ I.-Wei Chen and X;-H.Wang, "Sintering dense nanocrystalline ceramics without final stage grain growth", Nature 404 168-171 (2000).

${ }^{34}$ M.J. Lukic, L. Veselinovic, Z. Stojanovic, M.Macek-Krzmanc, I.Bracko, S.D.Skapin, S. Markovic, D.Uskokovic, "Peculiarities in Sintering Behavior of Ca-Deficient Hydroxyapatite Nanopowders", Mater. Lett. 68 331-335 (2012).

${ }^{35}$ J.G.Li, T.Hashida, "In situ formation of hydroxyapatite-whisker ceramics by hydrothermal hotpressing method", J. Am. Ceram. Soc. 89 3544-3546 (2006).

${ }^{36}$ Y. Liu, Z. Shen, "Dehydroxylation of hydroxyapatite in dense bulk ceramics sintered by spark plasma sintering”, J. Eur. Ceram. Soc. 32 2691-2696 (2012).

${ }^{37}$ Paul Allen Williams, Subrata Saha, "The electrical and dielectric properties of human bone tissue and their relationship with density and bone mineral content", Annals of Biomedical Engineering, 24 (2) 222-233 (1996).

${ }^{38}$ Nanomedicine: Technologies and Applications edited by Thomas J Webster, Woodhead publishing series in biomaterials: Number 49, ISBN 978-0-85709-233-5, 2012.

${ }^{39}$ Hideatsu Maeda and Eiich Fukada, "Effect of water on piezoelectric, dielectric, and elastic properties of bone", Biopolymers, 21(10) 2055-2068 (1982).

40 S.A.Tofail, Joanna Bauer, "Electrically Polarized Biomaterials", Advanced Materials, 28(27) 5470-5484

${ }^{41}$ Vuk Uskoković, "The Role of Hydroxyl Channel in Defining Selected Physicochemical Peculiarities Exhibited by Hydroxyapatite", RSC Adv. 5 36614-36633 (2015).

42 Jacob L. Jones, Benjamin J. Iverson and Keith J. Bowman, "Texture and Anisotropy of Polycrystalline Piezoelectrics", Journal of the American Ceramic Society, 90 (8) 2297-2314 (2007). 
${ }^{43}$ S. A. M. Tofail, D. Haverty, F. Cox, J. Erhart, P. Hána, and V. Ryzhenko, "Direct and ultrasonic measurements of macroscopic piezoelectricity in sintered hydroxyapatite", Journal of Applied Physics, 105 064103.1-064103.6 (2009).

${ }^{44}$ H. Yan, H. Zhang, R. Ubic, M. Reece, Z. Shen, and Z. Zhang, "A Lead-Free High-Curie-Point Ferroelectric Ceramic, $\mathrm{CaBi}_{2} \mathrm{Nb}_{2} \mathrm{O}_{9}$ ",Adv. Mater., 17 1261-265 (2005).

${ }^{45} \mathrm{~V}$. Mamedov, "Spark plasma sintering as advanced PM sintering method", Powder Metallurgy, 45(4) 322-328 (2002).

${ }^{46}$ Abbasi A. Gandhi, Robert D. Gunning, Kevin M. Ryan and Syed A. M. Tofail, "The Role of Texturing and Densification on Optical Transmittance of Hydroxyapatite Ceramics", J Am Ceram Soc, 93 3773-3777 (2010).

${ }^{47}$ M. P. Mahabole, R. C. Aiyer, C. V. Ramakrishna, B. Sreedhar, and R. S. Khairnar, "Synthesis, characterization and gas sensing property of hydroxyapatite ceramic", Bull. Mater. Sci. 28 535545 (2005).

${ }^{48}$ N.A. Zakharov, V.P. Orlovskii, "Dielectric characteristics of biocompatible $\mathrm{Ca}_{10}\left(\mathrm{PO}_{4}\right)_{6}(\mathrm{OH})_{2}$ ceramics", Tech Phys Lett 27 629-631 (2001).

${ }^{49}$ J.P.Gittings, C.R.Bowen, A.C.E.Dent, I.G.Turner, F.R.Baxter, J. B.Chaudhuri, "Electrical characterization of hydroxyapatite based bioceramics", Acta Biomaterialia 5 743-754 (2009).

${ }^{50}$ Yumi Tanaka, Takeshi Iwasaki, Miho Nakamura, Akiko Nagai, Keiichi Katayama, and Kimihiro Yamashita, "Polarization and microstructural effects of ceramic hydroxyapatite electrets", Journal of Applied Physics 107 014107-014110 (2010). 


\section{List of Tables}

Table 1. Ferroelectric Curie temperature and the dielectric permittivity of the sintered composite at 250 $\mathrm{K}$ and $408 \mathrm{~K}$ at $1 \mathrm{kHz}$

\section{List of Figures}

Figure 1. XRD analyses of HA-BT (a) starting powders at $900^{\circ} \mathrm{C}$ and (b) sintered ceramics at $850^{\circ} \mathrm{C}$

Figure 2. FTIR spectra of HA-BT piezocomposites: (a) HA (b) HB75 (c) HB60 (d) HB40 (e) HB25

Figure 3. TGA analyses of (a) $\mathrm{HB}_{300} 40$ and (b) $\mathrm{HB}_{500} 40$ piezocomposites

Figure 4. Microstructure and EDS images of sintered piezocomposites of HB25 and HB75 by SPS

Figure 5. Change of microstructure of sintered piezocomposites of $\mathrm{HB}_{500} 40$ before and after polarization

Figure 6. Temperature dependence of $(\mathrm{a}, \mathrm{b})$ dielectric permittivity at $1 \mathrm{KHz}$ and $10 \mathrm{KHz}$ of sintered $\mathrm{HA}$ BT piezocomposites and (c) dielectric losses at $1 \mathrm{KHz}$ and $10 \mathrm{KHz}$ of sintered HB40 and HB60 piezocomposites

Figure 7 Pyroelectric behavior of (a) HA, (b) -(c) $\mathrm{HB}_{300} 40$ and (d)-(e) $\mathrm{HB}_{500} 40$ piezocomposites

Table 1. Ferroelectric Curie temperature and the dielectric permittivity of the sintered composite at 250 $\mathrm{K}$ and $408 \mathrm{~K}$ at $1 \mathrm{kHz}$

\begin{tabular}{|l|l|l|l|}
\hline Composition & Curie's Temperature $\left({ }^{\circ} \mathbf{C}\right)$ & $\begin{array}{l}\text { Dielectric } \\
\text { permittivity } \\
\text { at 250 K }\end{array}$ & $\begin{array}{l}\text { Dielectric } \\
\text { permittivity } \\
\text { at 408 K }\end{array}$ \\
\hline $\mathrm{HB}_{300} 75$ & 116 & 241 & 261 \\
\hline $\mathrm{HB}_{500} 75$ & 126 & 175 & 181 \\
\hline $\mathrm{HB}_{300} 60$ & 106 & 78.7 & 102 \\
\hline $\mathrm{HB}_{500} 60$ & 116 & 62.9 & 98 \\
\hline $\mathrm{HB}_{300} 40$ & 96.5 & 38.1 & 59.1 \\
\hline $\mathrm{HB}_{500} 40$ & 106.5 & 37.8 & 59.5 \\
\hline $\mathrm{HB}_{300} 25$ & 98.5 & 15.1 & 20.3 \\
\hline $\mathrm{HB}_{500} 25$ & 99.5 & 12.8 & 16.4 \\
\hline
\end{tabular}



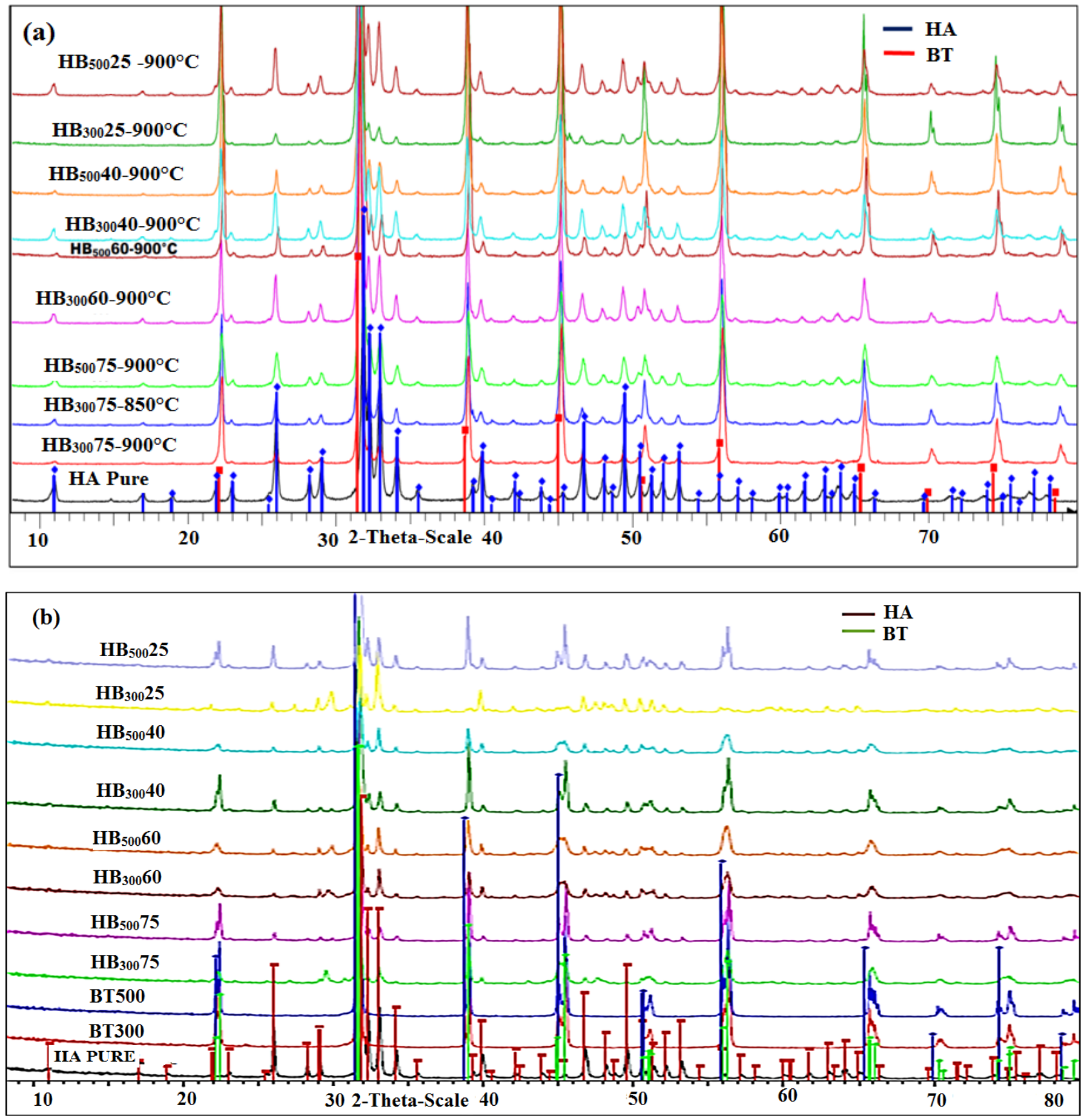

Figure 1. XRD analyses of HA-BT (a) starting powders at $900^{\circ} \mathrm{C}$ and (b) sintered ceramics at $850^{\circ} \mathrm{C}$ 

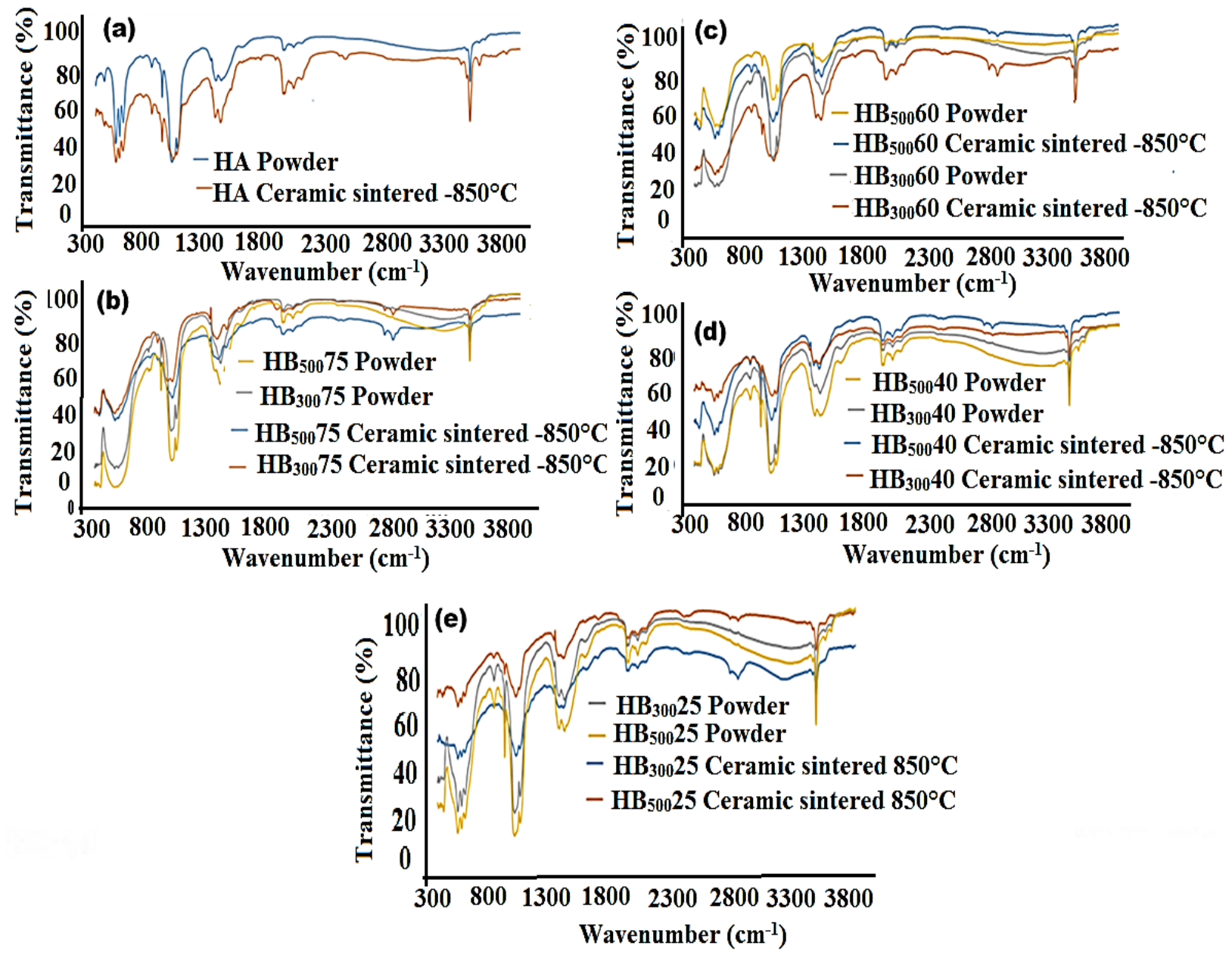

Figure 2. FTIR spectra of HA-BT piezocomposites: (a) HA (b) HB75 (c) HB60 (d) HB40 (e) HB25 

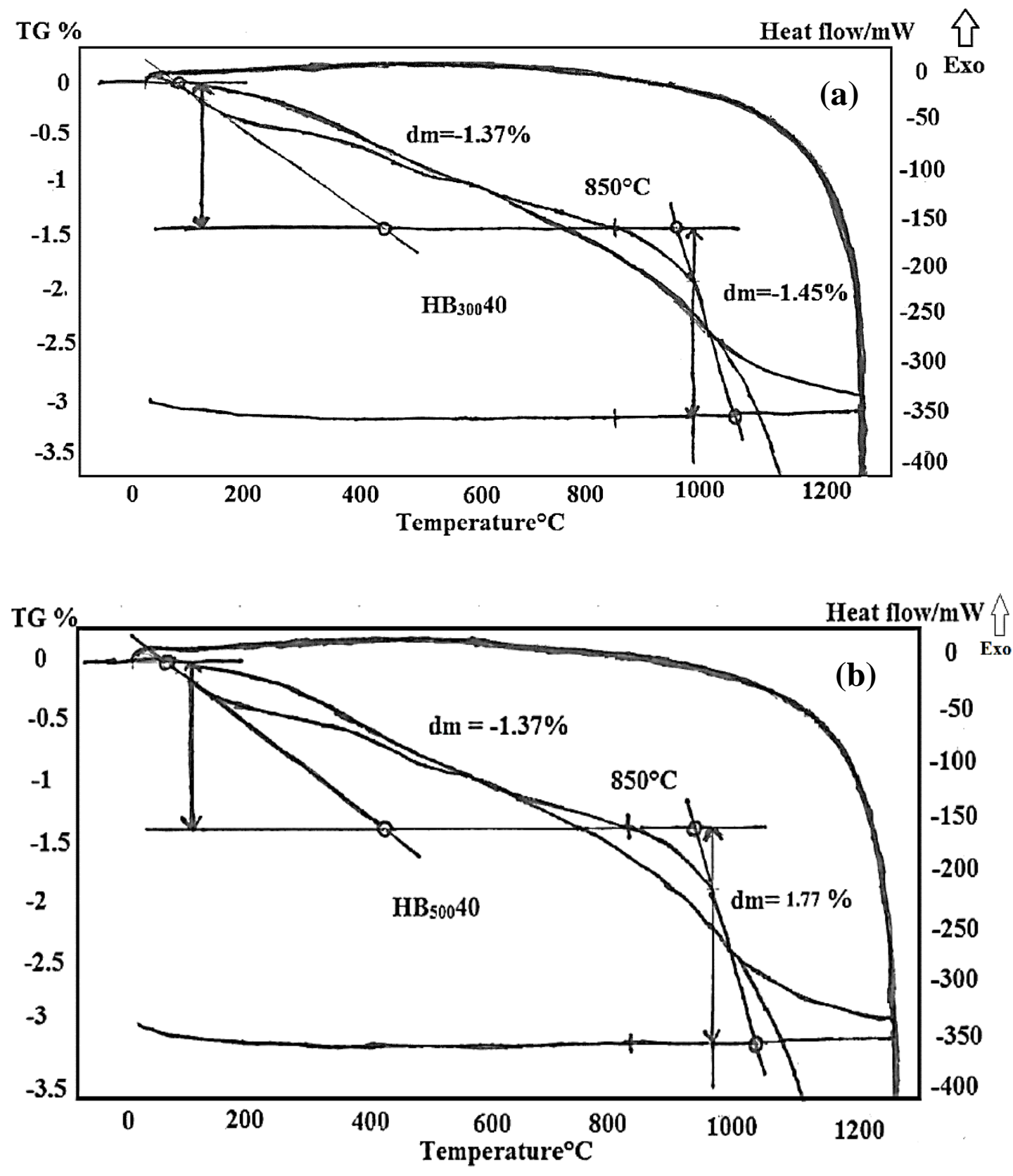

Figure 3. TGA analyses of (a) $\mathrm{HB}_{300} 40$ and (b) $\mathrm{HB}_{500} 40$ piezocomposites 

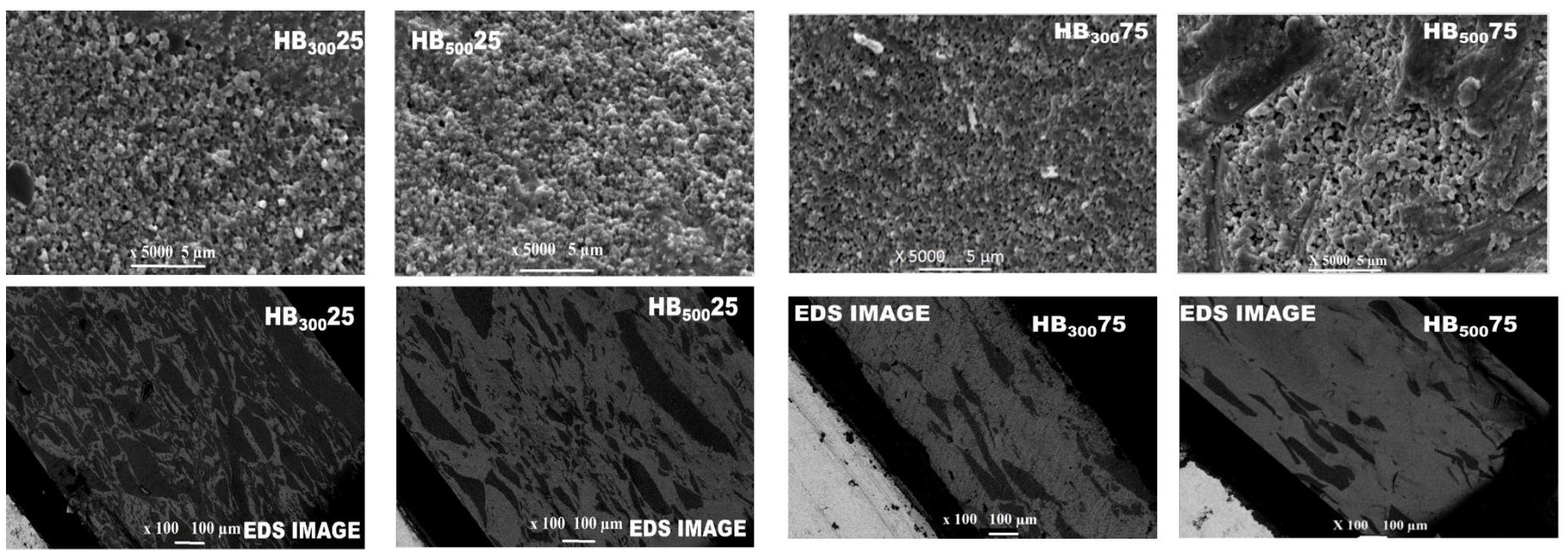

Figure 4. Microstructure and EDS images of sintered piezocomposites of HB25 and HB75 by SPS 

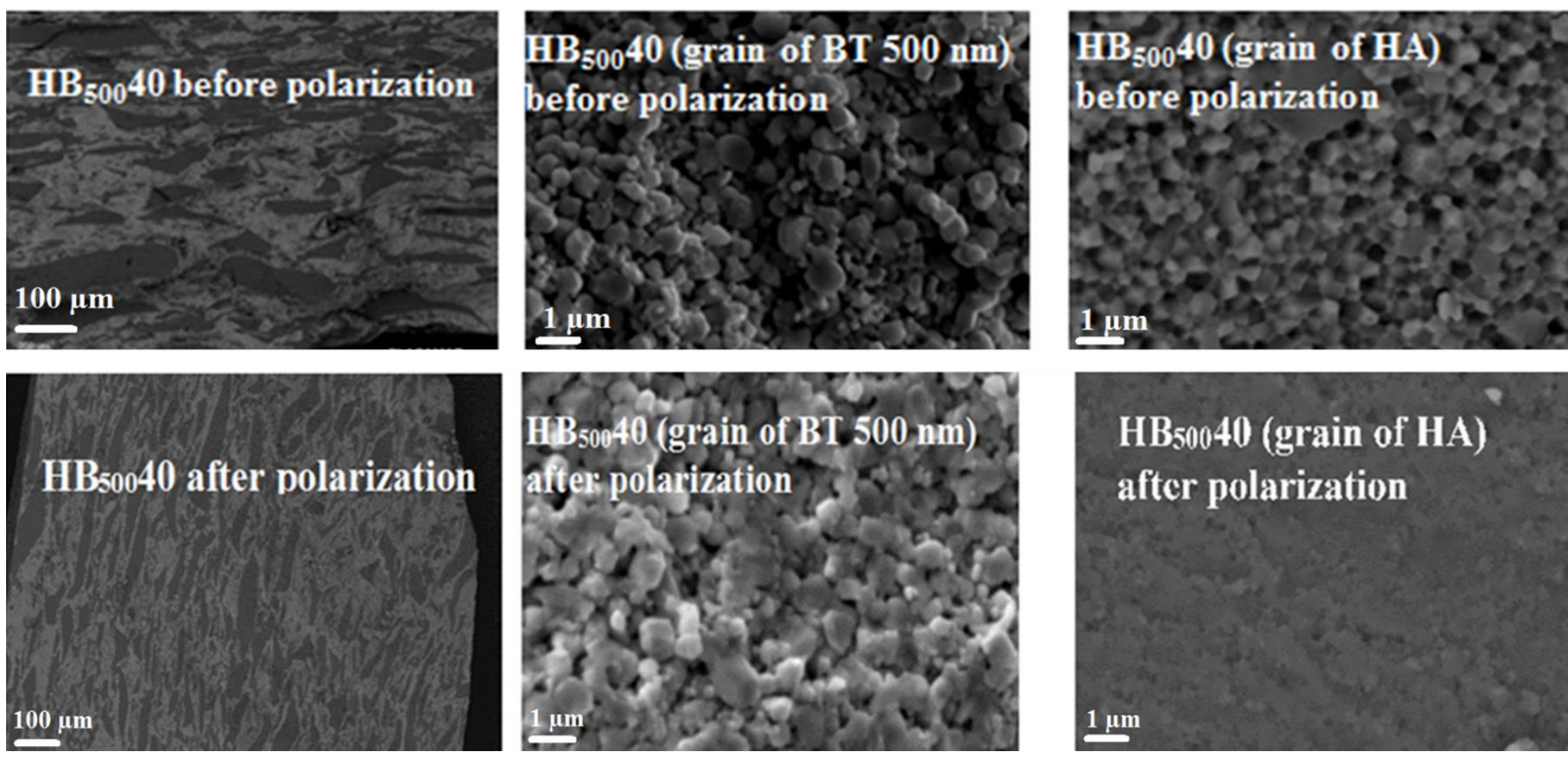

Figure 5. Change of microstructure of sintered piezocomposites of $\mathrm{HB}_{500} 40$ before and after polarization 

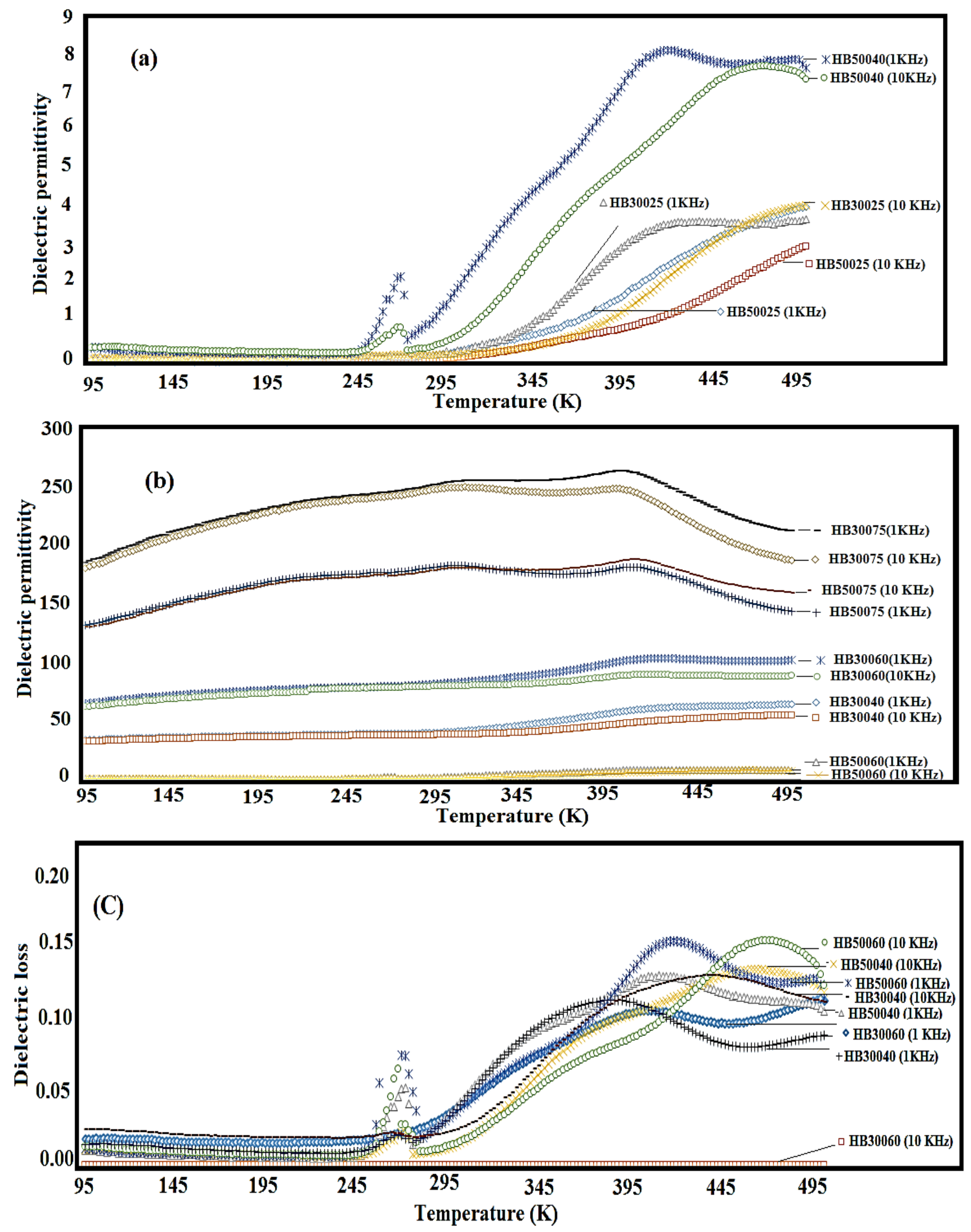

Figure 6. Temperature dependence of $(\mathrm{a}, \mathrm{b})$ dielectric permittivity at $1 \mathrm{KHz}$ and $10 \mathrm{KHz}$ of sintered $\mathrm{HA}$ BT piezocomposites and (c) dielectric losses at $1 \mathrm{KHz}$ and $10 \mathrm{KHz}$ of sintered HB40 and HB60 piezocomposites 

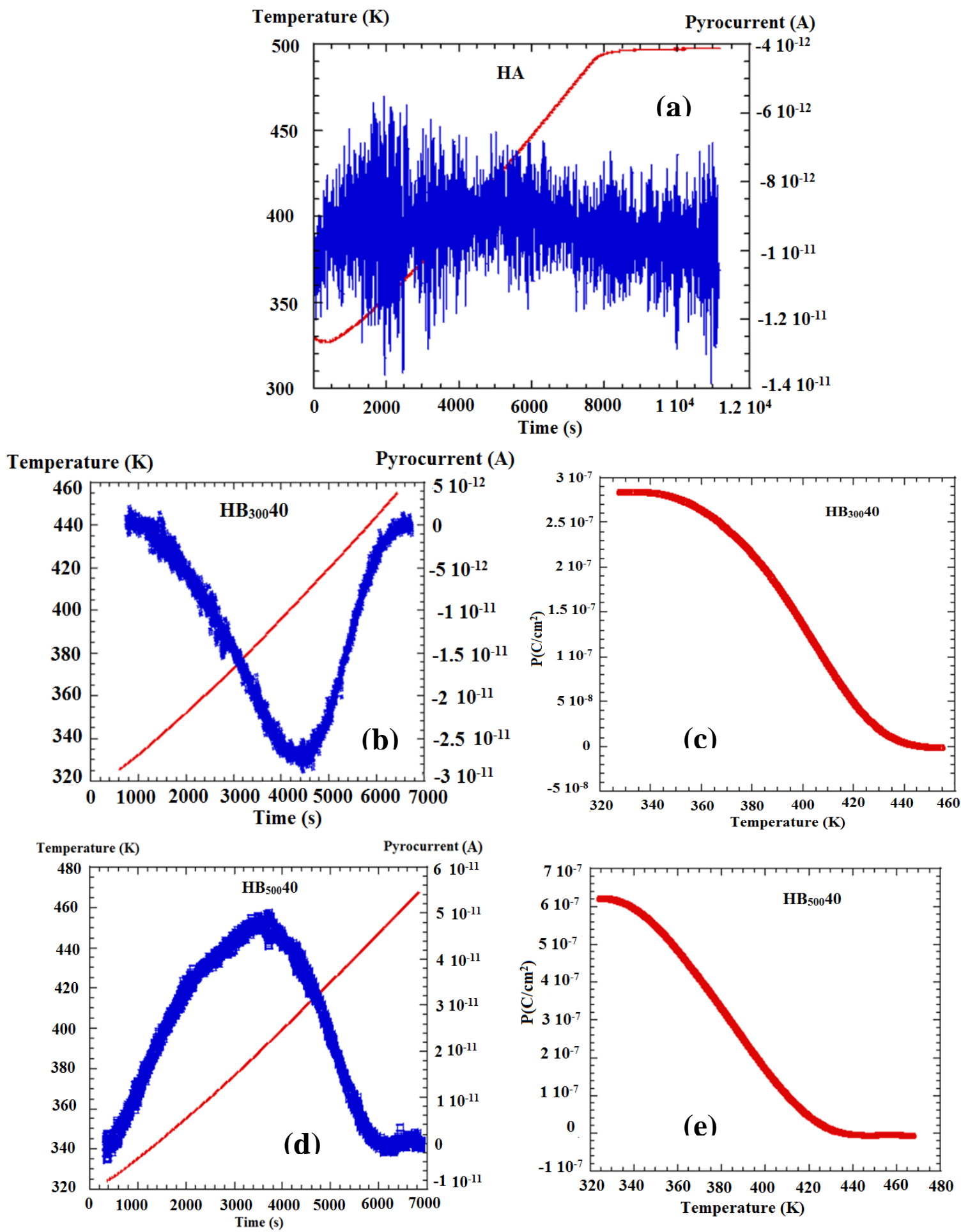

Figure 7 Pyroelectric behavior of (a) HA, (b) -(c) $\mathrm{HB}_{300} 40$ and (d)-(e) $\mathrm{HB}_{500} 40$ piezocomposites 